\title{
Embolization of incidental cerebral aneurysms using the Guglielmi detachable coil system
}

\section{Yuichi Murayama, M.D., Fernando Viñuela, M.D., Gary R. Duckwiler, M.D., Y. Pierre Gobin, M.D., and Guido Guglielmi, M.D.}

Division of Interventional Neuroradiology, University of California, Los Angeles, School of Medicine, Los Angeles, California

Guglielmi detachable coil (GDC) technology is a valuable therapeutic alternative to the surgical treatment of ruptured or incidental intracranial aneurysms. The authors describe their technical and clinical experience in the utilization of the GDC technique in patients who underwent endovascular occlusion for the treatment of incidentally found intracranial aneurysms.

One hundred fifteen patients with 120 incidentally found intracranial aneurysms underwent embolization using the GDC endovascular technique. Ninety-one patients were female and 24 were male. Patient age ranged from 13 to 80 years. In 64 patients the incidental aneurysms were discovered when unrelated nonneurological conditions indicated the need for angiography or magnetic resonance angiography (Group 1). Twenty patients who presented with incidental aneurysms that were discovered during treatment for an acutely ruptured aneurysm were treated in the acute phase of subarachnoid hemorrhage (SAH) (Group 2). Sixteen patients with incidental aneurysms were treated during the chronic phase of SAH (Group 3). Group 4 included 15 patients who had incidental aneurysms associated with brain tumors or arteriovenous malformations.

Angiographic results showed complete or near complete occlusion in 109 aneurysms (91\%) and incomplete occlusion in five aneurysms (4\%). Unsuccessful GDC embolization was attempted in six aneurysms $(5 \%)$. One hundred nine patients $(94.8 \%)$ remained neurologically intact or unchanged from initial clinical status. Five patients $(4.3 \%)$ deteriorated due to immediate procedural complications (overall immediate morbidity rate). All of these complications occurred in the first 50 patients treated earlier in this series. No clinical complications were observed in the last 65 patients. Follow-up cerebral angiograms were obtained in 77 patients with 79 aneurysms. The median clinical follow-up period was 16.3 months.

No recanalization was observed in the 52 completely occluded aneurysms. Of the 22 aneurysms with small neck remnants, eight (36\%) showed further thrombosis, 7 (32\%) remained anatomically unchanged, and seven (32\%) showed recanalization due to compaction of the coils. In one patient, a partially embolized aneurysm ruptured 3 years postembolization. In Groups 1 and 3, the average length 
of hospitalization was 3.3 days.

The evolution of the GDC technology has proved to provide safe treatment of incidental aneurysms (a morbidity rate of $0 \%$ was achieved in the last 65 patients). The topography of the aneurysm and the clinical condition of the patient did not influence final anatomical or clinical outcomes. The GDC technology also confers a positive economical impact by decreasing hospital length of stay and by eliminating the need for postembolization intensive care unit care.

\section{Key Words * cerebral aneurysm * endovascular therapy * embolization * Guglielmi detachable coil system * incidental aneurysm}

The increased utilization of magnetic resonance (MR) angiography, MR imaging, and helical computerized tomography (CT) angiography has improved our ability to detect unruptured intracranial aneurysms.[21,27,36]

The surgical management of incidental cerebral aneurysms remains controversial. Although numerous studies have reported a low surgical risk rate in the treatment of incidental aneurysms, the rates of surgical procedural morbidity and mortality may be influenced by specific factors such as aneurysm location and size, and by patient age and poor medical condition.

Previous reports in the literature have emphasized the safety and efficacy of the Guglielmi detachable coil (GDC) technique for the endovascular treatment of ruptured aneurysms.[6-8,19,22,24,31] This endovascular technique can also contribute to the overall treatment of patients harboring incidental aneurysms by allowing percutaneous aneurysm occlusion without need for craniotomy. This technique can also be used in an elderly population and in patients with severe cardiorespiratory or systemic diseases. This study describes immediate and long-term anatomical and clinical outcomes in 115 patients with incidental aneurysms treated with the GDC system.

\section{CLINICAL MATERIAL AND METHODS}

\section{Patient Population}

One hundred fifteen patients with 120 incidental cerebral aneurysms underwent GDC embolization at UCLA Medical Center from August 1991 to January 1998. Ninety-one patients (79\%) were women and $24(21 \%)$ were men, and age ranged from 13 to 80 years, with an average age of 51 years. Age distribution was as follows: 22 patients $(19.1 \%)$ were younger than 40 years of age, $80(69.6 \%)$ were between age 40 and 69 years, and $13(11.3 \%)$ were older than 70 years of age.

This patient population was classified into four groups. In 64 patients, 68 aneurysms were discovered incidentally during angiography, CT angiography, or MR angiography for an unrelated medical condition (Group 1).

Twenty patients (20 aneurysms) had multiple aneurysms discovered on cerebral angiography that was performed for acute subarachnoid hemorrhage (SAH) due to a ruptured aneurysm. All aneurysms were treated in the acute phase ( $<14$ days) of SAH, either by combined surgery and embolization or by embolization alone (Group 2). The ruptured aneurysm was clearly identified in most cases by the blood distribution on CT scanning of the head, aneurysm anatomical characteristics, surgical findings, and by the distribution of the arterial vasospasm. This aneurysm group was the first to be treated by the GDC technique or surgical clipping. 
Sixteen incidental aneurysms in 16 patients were revealed in a delayed procedure unrelated to the acute phase of SAH (Group 3). These patients were readmitted to the hospital for treatment of the incidental aneurysm after clinical recovery from initial SAH.

Group 4 included 16 incidental aneurysms found in 15 patients who were being treated for brain tumors, brain arteriovenous malformations, intracerebral hemorrhage, or coexisting aneurysms with mass effect. Patients' clinical presentation data are summarized in Table 1.

\begin{tabular}{|c|c|}
\hline $\begin{array}{c}\text { TABLE } 1 \\
\text { PRIMARV CL NICAL PRESENTATION IN } 115 \text { PATIEN } \\
\text { WITH INCIDENT INTRACRANIAL ANEU }\end{array}$ & $\begin{array}{l}\text { HO PRESENTED } \\
\text { is }\end{array}$ \\
\hline Clirical Presentation & No. of Patierts \\
\hline 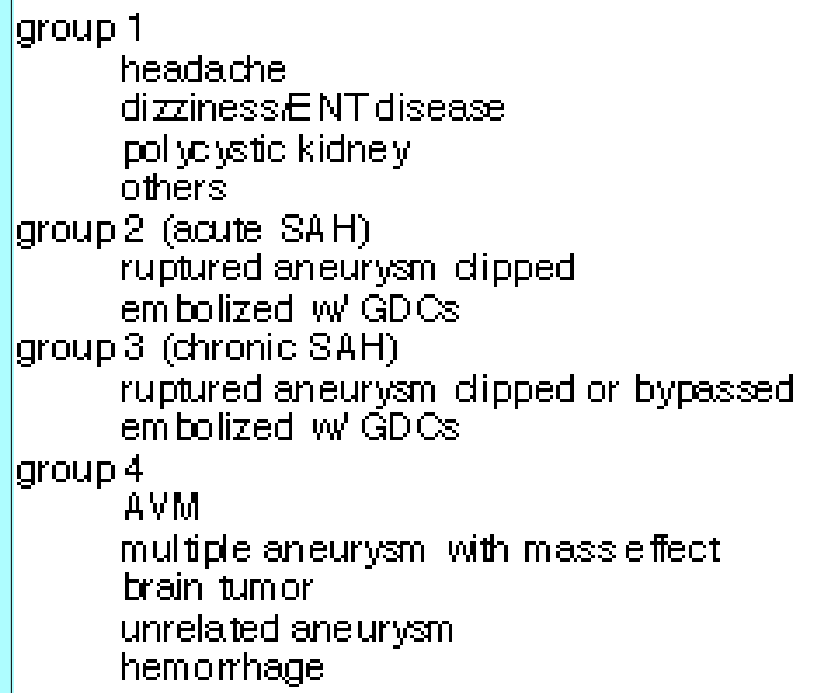 & $\begin{array}{r}64 \\
25 \\
4 \\
3 \\
32 \\
20 \\
6 \\
14 \\
16 \\
11 \\
5 \\
15 \\
6 \\
4 \\
3 \\
2\end{array}$ \\
\hline
\end{tabular}

\section{Indications for Aneurysm Treatment}

For all patients therapeutic alternatives were discussed among members of vascular neurosurgery and interventional neuroradiology departments. Indications for GDC treatment included: attempted surgical exploration (nine patients), refusal of surgery (17 patients), poor medical condition (11 patients), and elderly patients ( $>70$ years of age [13 patients]). In the remaining patients, the referring neurosurgeon from the community or from the medical center's neurosurgical team determined that the aneurysm posed a highly difficult surgical challenge.

\section{Description of Aneurysms}

Aneurysm Location. Eighty-seven aneurysms were located in the anterior circulation (73\%) and 33 in the posterior circulation (28\%) (Table 2). The most common location was the carotid ophthalmic/paraclinoid segment (recorded as superior hypophyseal or ophthalmic aneurysms) (35.8\%), followed by basilar artery (BA) tip (18\%), middle cerebral artery (MCA) (13\%), and anterior communicating arteries $(9 \%)$. 


\begin{tabular}{|cc|}
\hline \multicolumn{2}{|c|}{ TABLE 2 } \\
ANEURVSM LOCATION IN 115 PATIENTS WITH \\
INCIDENTAL ANEURVSMS
\end{tabular}

Size of Aneurysm. Eighty-seven aneurysms (72.5\%) were small (4-10 $\mathrm{mm}$ in their largest diameter); 27 $(22.5 \%)$ were large $(11-25 \mathrm{~mm})$; and six $(5 \%)$ were giant $(>25 \mathrm{~mm})$ (Table 3$)$.

\begin{tabular}{|c|c|c|c|c|}
\hline SIzE & $\begin{array}{l}120 \text { ANEUR } \\
\text { GOING TRE }\end{array}$ & $\begin{array}{l}\text { BLE } 3 \\
\text { IS IN } 1 \\
\text { ENT } w\end{array}$ & $\begin{array}{l}\text { ATIENT } \\
\text { GDOS }\end{array}$ & UNDER - \\
\hline & & & rysm s & \\
\hline Group & Aretrysms & Small & Large & Giant \\
\hline 1 & 68 & 44 & 19 & 5 \\
\hline 2 & 20 & 19 & 1 & 0 \\
\hline 3 & 16 & 14 & 2 & 0 \\
\hline 4 & 16 & 10 & 5 & 1 \\
\hline
\end{tabular}

Size of the Neck. Fifty-one aneurysms $(42.5 \%)$ had a small neck $(<4 \mathrm{~mm}), 64(53.3 \%)$ had a wide neck (> $4 \mathrm{~mm}$ ), and five (4.2\%) were fusiform (Table 4). All large- and giant-sized aneurysms, except fusiform aneurysms, had necks wider than $4 \mathrm{~mm}$ in diameter.

\begin{tabular}{|c|c|c|c|c|}
\hline \multirow[b]{3}{*}{ Group } & \multicolumn{4}{|c|}{$\begin{array}{c}\text { TABLE } 4 \\
\text { SIZE OF NECK IN } 120 \text { ANEURVSMS }\end{array}$} \\
\hline & \multirow{2}{*}{$\begin{array}{c}\text { No. of } \\
\text { Aneurysms }\end{array}$} & \multicolumn{3}{|c|}{ Neck Size } \\
\hline & & Small & Wi de & Fusif orm \\
\hline 1 & 68 & 25 & 40 & 3 \\
\hline 2 & 20 & 13 & 7 & 0 \\
\hline 3 & 16 & 9 & 7 & 0 \\
\hline 4 & 16 & 4 & 10 & 2 \\
\hline
\end{tabular}




\section{GDC Embolization of Aneurysms}

A detailed description of the GDC technique for acutely ruptured aneurysms has already been published.[31] This same technique was applied in the endovascular GDC embolization of the incidental aneurysms in this series.

The GDC embolization was always preceded by obtaining a complete cerebral angiogram. Information on number, size, and location of aneurysms, as well as anatomical characteristics of the circle of Willis and brachycephalic arteries, was always obtained.

The patient recieved a general anesthestic and underwent systemic heparinization throughout the procedure. We use the same systemic heparinization regime for patients who are undergoing embolization for a ruptured aneurysm or an incidental aneurysm. Systemic heparinization was reversed in all patients with the injection of protamine sulfate $(10 \mathrm{mg} / 1000 \mathrm{U}$ heparin), with the exception of those patients whose aneurysms had some protrusion of the coils into the lumen of the parent artery. In those cases, systemic heparinization was not reversed but was continued for 24 hours in the intensive care unit.

A No. 1.8 or 2.1 French microcatheter was positioned in the sac of the aneurysm utilizing high-quality fluoroscopy and roadmapping capabilities. We did not find any technical differences in catheterizing ruptured versus incidental aneurysms. Those aneurysms that were treated in the presence of post-SAH arterial vasospasm required slightly different endovascular manipulations. The endovascular manipulation of microcatheters in patients with acute SAH did not elicit an increased incidence of vasospasm. The GDCs were sequentially deposited and detached into the aneurysm until a tight coil packing was achieved.

The rate of aneurysm obliteration was evaluated by immediate postembolization angiography in multiple projections. These anatomical results were classified as complete occlusion, which was defined as no contrast filling of the aneurysm dome, body, and neck; small neck remnant, which was defined as residual filling of part of the aneurysm; incomplete occlusion, which was defined as some contrast filling of the dome still observed due to incomplete GDC packing; and attempted occlusion, which was defined as endovascular intervention attempted but GDC embolization could not be performed.

The GDC embolization of incidental aneurysms was usually performed on admission day (defined as Day 0). The patients were then admitted overnight in the neuroobservation unit and transferred to the neurosurgical ward the next morning (Day 1). Patients consumed a normal diet and were able to walk in the ward, and they were discharged by Day 2 or 3 posttreatment (except those patients in the acute phase of SAH or those with coexisting arteriovenous malformations or intracranial tumors).

\section{Angiographic Follow-up Studies}

Follow-up angiograms were usually obtained at 6 months postembolization if the aneurysm had been completely or near completely occluded. In those patients with incompletely embolized aneurysms, angiographic follow-up evaluation was scheduled at 3 months postembolization. Subsequent follow-up angiography was scheduled at 12 months postembolization. In other patients yearly follow-up angiography was performed for up to 5 years. In some patients, however, follow-up angiography could not being obtained due to patient refusal or difficulty in communicating when the patient lived abroad.

\section{RESULTS}




\section{Immediate Anatomical Outcome}

Complete GDC occlusion of the incidental aneurysm was achieved in 76 aneurysms (63.3\%) (Table 5). A small neck remnant was detected in 33 aneurysms (27.5\%), and an incomplete occlusion was performed in five aneurysms $(4.2 \%)$.

\begin{tabular}{|c|c|c|c|c|c|}
\hline \multirow[b]{3}{*}{$\begin{array}{l}\text { Aneurym \& } \\
\text { Neck Size }\end{array}$} & \multicolumn{5}{|c|}{$\begin{array}{c}\text { TABLE } 5 \\
\text { IMMEDIATE ANGOGRA PHIC OUTCOME IN } 115 \text { PATIENTS (120 ANEURYSMS) } \\
\text { POST-GDC TREATMEN T^ }\end{array}$} \\
\hline & \multicolumn{5}{|c|}{ No. of Areurysms [\%] } \\
\hline & Total & $\begin{array}{l}\text { Complete } \\
\text { Occlusion }\end{array}$ & $\begin{array}{c}\text { Neck } \\
\text { Remnant }\end{array}$ & $\begin{array}{l}\text { Inc omplete } \\
\text { Occlusion }\end{array}$ & $\begin{array}{l}\text { Ast empted } \\
\text { Occlusion }\end{array}$ \\
\hline $\begin{array}{l}\text { S8 } \\
\text { SNul } \\
\text { large } \\
\text { giant } \\
\text { total }\end{array}$ & $\begin{array}{r}52(43) \\
35(29) \\
27(23) \\
6(5) \\
120\end{array}$ & $\begin{array}{l}44(85) \\
18(51.4) \\
12(44) \\
2(3.3) \\
76(53)\end{array}$ & $\begin{array}{c}8(15) \\
9(25.7) \\
12(44) \\
4(6.6) \\
33(27)\end{array}$ & $\begin{array}{l}0 \\
3(8.5) \\
2(7) \\
0 \\
5(4)\end{array}$ & $\begin{array}{l}0 \\
5(14.3) \\
1(3) \\
0 \\
6(5)\end{array}$ \\
\hline
\end{tabular}

Six aneurysms (5\%) could not be embolized due to their wide neck. Surgical clipping was performed in two cases, and three aneurysms were treated conservatively. At present, the utilization of 3-dimensional GDCs and the balloon-assisted technique allows definitive GDC occlusion of this type of aneurysm.

\section{Immediate Clinical Outcome}

All patients were clinically evaluated prior to hospital discharge. One hundred nine patients (94.8\%) were neurologically intact or remained clinically unchanged. Table 6 provides a summary of outcome and morbidity data.

\begin{tabular}{|c|c|c|c|c|c|c|c|}
\hline MORB DI & N AND CL $\mathrm{N}$ & CAL OU & COME IN F & $\begin{array}{l}\text { RELATION } \\
\text { MED }\end{array}$ & $\begin{array}{l}\text { BLE } 6 \\
\text { LCATION AND SIZE } \\
\text { CONDITION* }\end{array}$ & ANEURVSMS & TIENT AGE AND \\
\hline & Aneury & & & & & Immediate & Longterm \\
\hline Treatment & Location & Size & Age (yrs) & Condition & Complication & Outcome & Outcome \\
\hline 1991 & MCA & $S B$ & 75 & normal & throm boem bolic & hemianopia & hemianopia \\
\hline 1992 & ophthal & Sho & 27 & normal & coil migration & in tact & in tact \\
\hline 1992 & PCon & Sin & 53 & normal & throm boem bolic & in tact & in tact \\
\hline $1992 \dagger$ & PCOA & LAN & 62 & normal & FU rupture & $\begin{array}{l}\text { in tact (after } \\
\text { 1stembol) }\end{array}$ & $\begin{array}{l}\text { HP (after } \\
\text { 2nd embol) }\end{array}$ \\
\hline 1993 & MCA & Sho & 41 & normal & throm boem bolic & hemi paresis & hemiparesis \\
\hline 1994 & ophthal & Sho & 80 & normal & hypotension & mono plegia & mono plegia \\
\hline 1994 & POOA & $S B$ & 63 & normal & rupture & hemi paresis & in tact \\
\hline 1995 & $\mathrm{BA}$ tip & SB & 37 & normal & throm boem bolic & hemianopia & hemianopia \\
\hline 1997 & suphypo & Sho & 70 & normal & throm boem bolic & intact & in tact \\
\hline $\begin{array}{l}\text { * Abtrevi } \\
\text { rior comm } \\
=\text { small an } \\
\text { † Patient } \\
\text { procedura. }\end{array}$ & $\begin{array}{l}\text { ons: emt } \\
\text { cating as } \\
\text { ffered ny }\end{array}$ & ire & heur ys & $\begin{array}{l}U=\text { foll } \\
\text { eurysm } \\
\text { Juring } f\end{array}$ & thal $=0 \mathrm{pt}$ & $\begin{array}{l}\text { HP }=\text { hemi } \\
\text { superior } \mathrm{r} \\
\text { dition to th }\end{array}$ & $\begin{array}{l}\mathrm{PCOA}=\mathrm{pos} \\
\text { sial artery; } \mathrm{S} \\
\text { with immedis }\end{array}$ \\
\hline
\end{tabular}

There were eight immediate procedural complications. Seven of these complications occurred in the first 50 patients who underwent GDC embolization between 1991 and 1995. In the remaining 65 patients, 
who were treated between 1995 and 1998, there was only one procedural complication and the combined mortality/morbidity rate was $0 \%$.

Untoward cerebral embolization was observed in six patients (5\%), and three of these patients were neurologically intact after receiving intraarterial thrombolytic therapy.

Perforation of the aneurysm occurred in one patient $(0.9 \%)$. This aneurysm was completely occluded by GDCs immediately after perforation, and this patient developed a transient postembolization hemiparesis, which totally recovered by 3 -month follow-up examination. One 80 -year-old patient developed a postembolization lower-extremity monoplegia. Immediate cerebral angiography failed to show an embolic occlusion of a cerebral artery. It is possible that this neurological deficit was related to a hemodynamic more than an embolic phenomenon. The patient continued to have a mild right-arm weakness.

These procedural complications occurred in seven anterior circulation aneurysms (two MCA, three ophthalmic/superior hypophysial, and one posterior communicating artery aneurysm) and one BA tip aneurysm. Five $(4.3 \%)$ of these eight patients experienced an immediate postembolization neurological deficit (overall procedural morbidity). There was one death unrelated to the GDC treatment; this patient presented with SAH and severe symptomatic vasospasm, and she developed a postangioplasty intraparenchymal hemorrhage probably related to an hemorrhagic transformation of an ischemic stroke after severe symptomatic vasospasm.

\section{Hospital Length of Stay}

The average period of hospitalization was 3.3 days in Group 1, 17 days in Group 2, 3.1 days in Group 3, and 6.7 days in Group 4 patients. In Groups 2 and 4, the incidental aneurysms were treated endovascularly after treatment of coexisting ruptured aneurysms or brain tumors.

\section{Long-Term Anatomical Outcome}

Follow-up cerebral angiograms were obtained in 77 patients (79 aneurysms). The median clinical follow-up period was 16.3 months.

No aneurysm recanalization was observed in the 52 completely occluded aneurysms (Fig. 1). In the 22 aneurysms with small neck remnants, eight (36\%) showed further aneurysm thrombosis, seven (32\%) remained anatomically unchanged, and seven $(32 \%)$ showed aneurysmal recanalization due to coil compaction into the body and dome of the aneurysm. In these recanalized aneurysms, additional embolization treatment achieved complete aneurysm occlusion in three patients, successful surgical clipping was performed in one, and three patients were treated conservatively. 


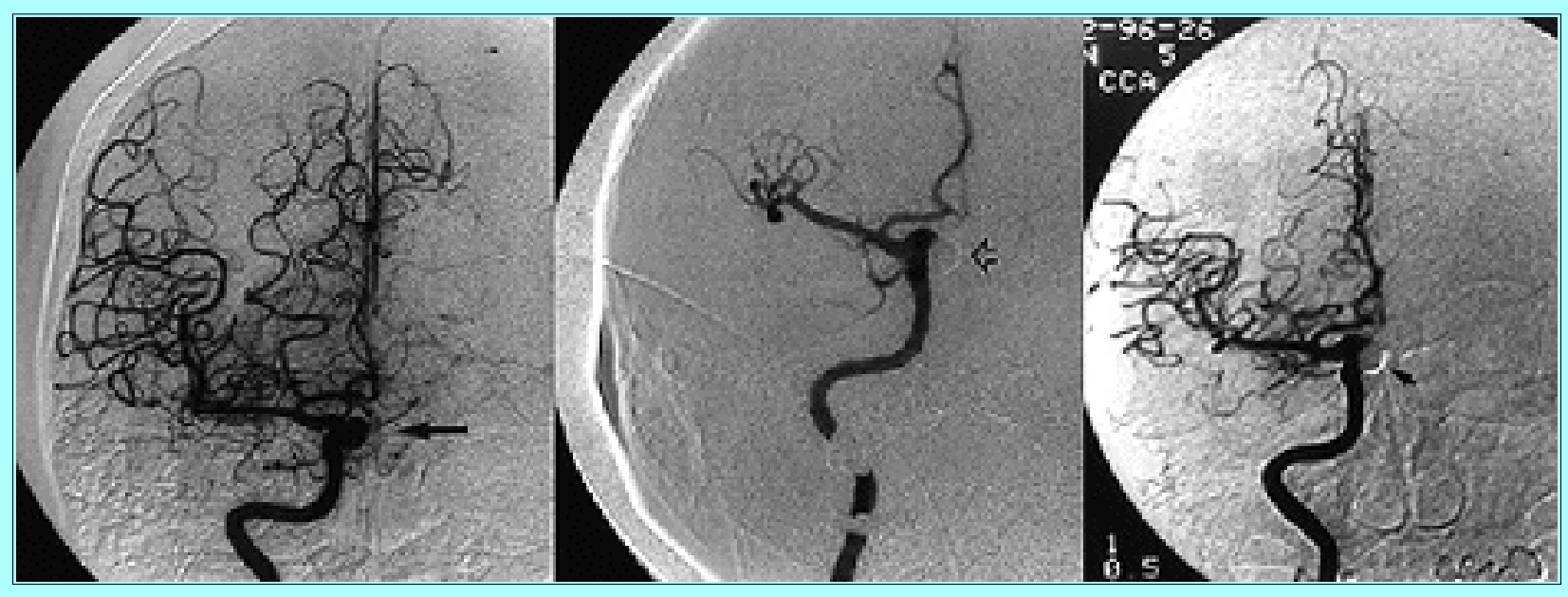

Fig. 1. Angiographic study illustrating long-term complete GDC embolization. Left: Right internal carotid angiogram showing an unruptured superior hypophysial aneurysm (arrow). Center: Immediate postembolization angiogram showing complete GDC occlusion of the aneurysm with preservation of the internal carotid artery lumen (open arrow). Right: Follow-up angiogram at 20 months demonstrating persistent complete aneurysm obliteration with GDCs (arrowhead).

Of the five incompletely treated aneurysms, a postembolization, clinically silent, parent-artery occlusion occurred in one patient; surgical clipping of the aneurysm was performed in one patient, and a parent artery occlusion with detachable balloons was performed in one patient. One patient was treated conservatively. In another patient, a partially embolized large posterior communicating aneurysm ruptured 3 years later and produced a severe right hemiparesis and aphasia (Fig. 2).
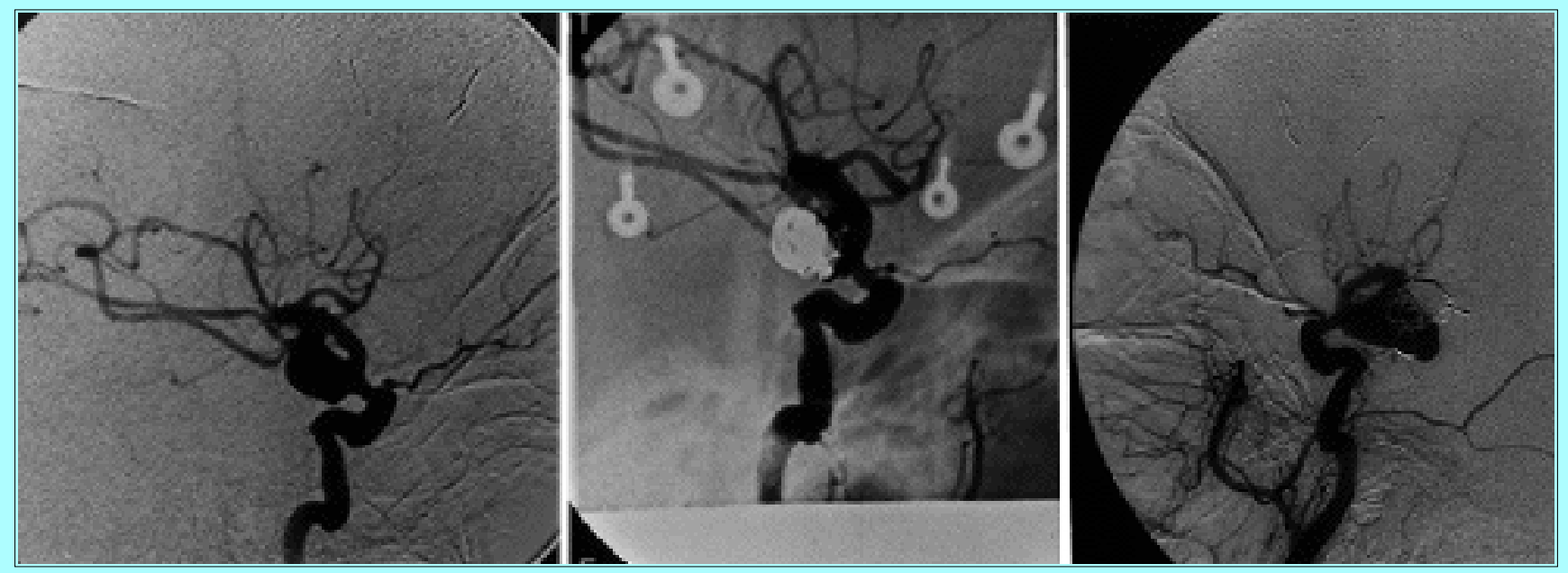

Fig. 2. Angiographic study illustrating process of long-term aneurysmal rupture. Left: Left internal carotid angiogram showing a large carotid-posterior communicating artery aneurysm with a wide neck. Center: Immediate postembolization angiogram demonstrating incomplete aneurysm occlusion, with a body and neck remnant. Right: Three years postembolization the patient suffered SAH. This cerebral angiogram shows coil compaction and recanalization of neck and body of the aneurysm.

\section{Long-Term Clinical Outcome}

In the 77 patients in whom a follow-up cerebral angiogram was obtained, 71 patients were neurologically intact or remained neurologically unchanged, and five patients showed a permanent neurological deficit. 
There were three delayed deaths unrelated to the GDC procedure (severe endocarditis, acquired immune deficiency syndrome, and an unknown cause).

\section{DISCUSSION}

Cerebral aneurysms are one of the major causes of hemorrhagic stroke in patients with cerebrovascular disease. Although surgical and endovascular techniques for the treatment of intracranial aneurysms have improved, the overall outcome for aneurysm-related SAH still remains unsatisfactory.[14] The risk of a catastrophic hemorrhage with long-term severe consequences or death can be eliminated if unruptured aneurysms can be identified and successfully occluded before rupture.

Many vascular neurosurgeons advocate aneurysm clipping based on positive personal experience in the therapeutic management of incidental aneurysms.[1,5,9,10,12,15,16,20,23,25,28,29,35] The current combined morbidity/mortality rate related to the neurosurgical clipping of an incidental cerebral aneurysm ranges between 5 and $10 \% \cdot[1,5,10,15,16,23,28,29]$ The indication for surgical treatment of incidental aneurysms is influenced by location and size of the aneurysm, patient age, and medical conditions. The aggressive treatment of incidental aneurysms can only be indicated if the risk of natural history of the disease is higher than the risk of an aggressive therapeutic management.

\section{Natural History of Unruptured Aneurysms}

Several studies have reported that the incidence of intracranial aneurysms in the general population ranges between 0.2 and 9\%, with an accepted average prevalence of 5\%.[3,4,11,13,17,21,30] These data suggest that incidental aneurysms constitute a significant impact on public health.[32] The incidence of SAH from intracranial aneurysms appears to increase with age. The rate of bleeding in patients with unruptured aneurysms is approximately 1 to $2 \%$ annually.[1,2,4,13,26,33,34] With a 1 to $2 \%$ annual risk of aneurysm rupture and 50\% morbidity/mortality rate associated with each hemorrhage, the natural history of untreated, unruptured aneurysms appears to be poor.[13]

\section{Significant Predictor of Aneurysm Rupture}

Size of Aneurysms. The significant relationship of aneurysm size to risk of hemorrhage was reported by Wiebers and colleagues.[34] In their study, zero of 102 aneurysms smaller than $10 \mathrm{~mm}$ in diameter ruptured, and 15 of 51 aneurysms $10 \mathrm{~mm}$ or greater ruptured during a mean clinical follow-up period of 8.3 years. The authors reported that unruptured aneurysms $10 \mathrm{~mm}$ in diameter or greater have a "fairly high" (29\%) probability of rupture. Therefore, they concluded that patients with aneurysms of this size should be strongly considered as candidates for surgical clipping.

Piepgras[23] reported basic guidelines for the treatment of incidental aneurysms, concluding that those that are greater than $10 \mathrm{~mm}$ should be treated in most patients and aneurysms 7 to $9 \mathrm{~mm}$ in diameter should be treated if found in young and middle-aged individuals. He recommended 2 years of follow-up cerebral angiography in patients with aneurysms $5 \mathrm{~mm}$ or smaller in diameter. However, Asari and Ohmoto[2] reported rupture of aneurysms less than $5 \mathrm{~mm}$ in diameter that previously had been found incidentally. These controversial statements in the neurosurgical literature highlight the concept that size is one of many factors (for example, congenital mesenchymal abnormalities, aneurysm location, local flow dynamics, systemic hypertension, etc.) that influence the natural history of intracranial aneurysms.

\section{Relationship of Aneurysm Size to Outcome}


It is well accepted that large aneurysms $(>/=10 \mathrm{~mm})$ are associated with a higher surgical morbidity rate compared with small aneurysms. Solomon, et al.,[29] reported that aneurysm size had significant influence on patients' surgical clinical outcome. The combined morbidity and mortality rate for unruptured aneurysms was $0 \%$ for aneurysms less than $10 \mathrm{~mm}$ in size, $6 \%$ for aneurysms between $10 \mathrm{~mm}$ and $25 \mathrm{~mm}$, and $20 \%$ for aneurysms greater than $25 \mathrm{~mm}$. Khanna, et al.,[16] have reported that a 25-mm-diameter aneurysm had a fourfold higher risk of poor outcome after surgery compared to a 5-mm-diameter aneurysm.

Technical or clinical deficits associated with the GDC embolization are not significantly influenced by size or location of incidental aneurysms. The GDC procedural morbidity rate has been significantly decreased by utilization of the latest technical developments. This was demonstrated when we analyzed the distribution of deficits associated with GDC embolization in this series. Seven of the eight procedural complications occurred between 1991 and 1995, and only one transient thromboembolic complication and no aneurysm perforation occurred in the most recent 65 patients with incidental aneurysms who underwent treatment between 1995 and 1998.

In incidental aneurysms treated with GDCs, the aneurysm size and/or neck size did not influence clinical outcome, but they did influence anatomical outcome. Small-size/wide-neck aneurysms presented the largest technical challenge to the GDC technology.[31] Incomplete GDC embolization in this type of aneurysm may produce aneurysm recanalization, and these aneurysms require strict angiographical follow up, additional embolization treatment, and/or surgical intervention. The present use of the balloon-assisted technique described by Moret, et al.,[18] in the treatment of wide-neck aneurysms has dramatically improved the GDC anatomical results (Fig. 3). However, this technique requires sophisticated handling of two endovascular catheter systems, and in inexperienced hands, it may increase the risk of aneurysm rupture or cerebral embolic complications.
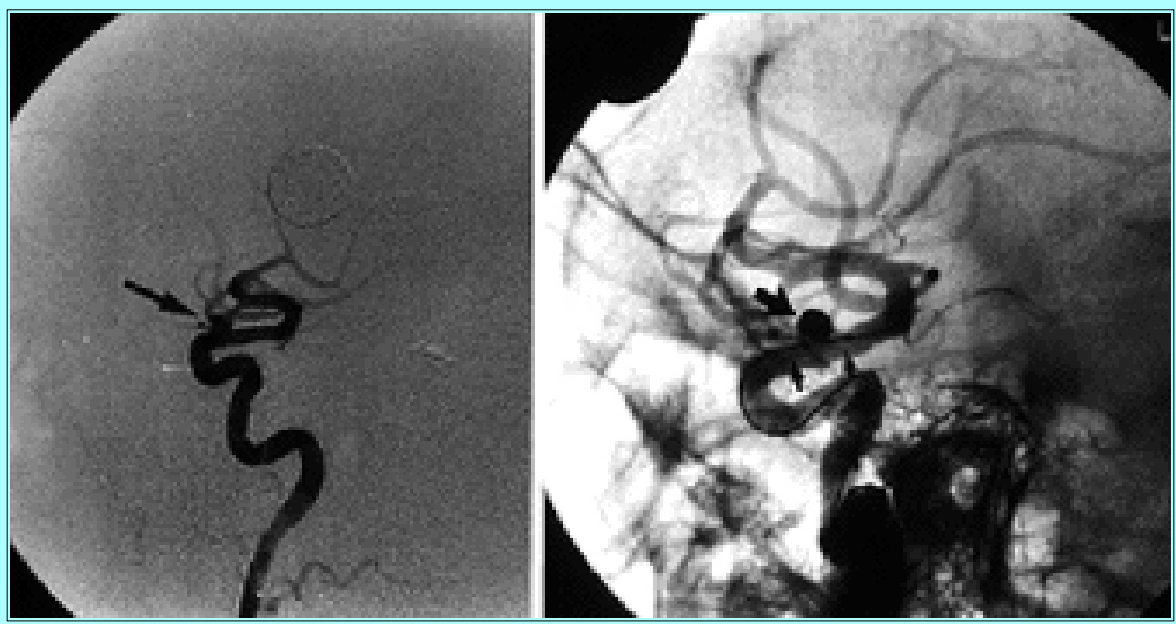

Fig. 3. Angiograms showing GDC embolization with balloon remodelling technique. Left: Left internal carotid angiogram showing a small, saccular wide-neck carotid-ophthalmic aneurysm (arrow). The GDCs were deposited while a balloon obliterated the neck of the aneurysm. Right: Immediate, nondigital subtraction postembolization angiogram showing aneurysm occlusion by GDCs (large arrow) and an already deflated balloon deposited across the neck of the aneurysm (small arrowheads).

In our series, a satisfactory (complete and small-neck remnant) embolization was achieved in $91 \%$ of aneurysms. However, in the long-term angiographic follow-up period, $32 \%$ of aneurysms with a small-neck remnant that were observed on the immediate postembolization angiography showed 
aneurysm recanalization, and one incompletely embolized aneurysm ruptured 3 years postembolization. Although there has not been a case of postembolization rupture in aneurysms with a small-neck remnant, strict follow-up angiography is mandatory when a complete embolization is not achieved.

\section{Relationship of Aneurysm Location to Clinical Outcome}

In the neurosurgical experience the topography of incidental aneurysms plays a role in whether the surgical procedure is indicated.[15,35] Most studies reporting the surgical outcome in patients with incidental aneurysms have excluded posterior circulation aneurysms. The presence of eloquent perforating arteries and the need for manipulation of cranial nerves to clip posterior fossa aneurysms are the most common causes of operative morbidity.

Rice, et al.,[25] have reported excellent surgical outcomes in patients treated for posterior circulation aneurysms, with a $4.2 \%$ morbidity/mortality rate; however, giant aneurysms were excluded in the study. Khanna, et al.,[16] have reported that an aneurysm in the posterior circulation was associated with an almost 10-fold higher risk of poor outcome following surgery compared to those located in the anterior circulation.

Unlike the outcome rates for surgical intervention, GDC embolization of aneurysms in the posterior fossa did not have an increased morbidity/mortality rate (morbidity rate 3\%). Aneurysms of the BA tip were one of the most commonly encountered aneurysms in this study. Positioning of the microcatheter in the aneurysm was relatively simple due to the favorable vascular anatomy.

Aneurysms in the MCA present an anatomical challenge due to the overlapping of the MCA branches over the aneurysm neck. It is essential to find the right angiographic view that allows perfect visualization of the aneurysm neck while delivering the GDCs. The drawback of blind GDC embolization of MCA aneurysms is the risk of local arterial branch occlusion and/or distal, immediate, or delayed embolic complications. The complementary use of CT angiography has facilitated the anatomical exploration of the MCA region. The 3-dimension rotation of this area allows very accurate identification of the neck of the MCA aneurysm and its relationship with surrounding arterial branches.

\section{Relationship of Patient Age and Medical Condition to Clinical Outcome}

Patient age and medical condition significantly impact clinical outcome after surgical intervention. Khanna, et al.,[16] have reported that a 70-year-old patient has over a sixfold higher risk of a poor outcome following surgery compared to a 30-year-old patient. Poor medical condition also increases the risk of operative morbidity.

Surgical treatment of patients with unruptured aneurysms associated with cerebral ischemia has been associated with a two- to fivefold higher incidence of poor outcome when compared to patients presenting without cerebral ischemia. In our series, three (15\%) of 13 patients over 70 years of age showed a higher incidence of morbidity.

Eleven patients (10\%) were in poor medical condition (three with renal failure, three with cerebral ischemia, three with cardiac failure, one who was pregnant, and one who had received a liver transplant). All of these patients in poor medical condition underwent the GDC aneurysm embolization without clinical complications.

The most common complication associated with GDC aneurysm embolization was intracranial embolic 
complications (5\%). This complication has been dramatically reduced by using appropriate systematic anticoagulation therapy during the endovascular procedure.

Aneurysm perforation during GDC embolization is very unusual $(0.7 \%)$. The most common technical mistakes associated with this complication are an inappropriate position of the microcatheter in the aneurysm and the selection of incorrectly sized GDCs. The recent development of soft GDCs allows a safer and denser packing of the aneurysm, which reduces the risk of aneurysm rupture and recanalization.

\section{Length of Hospitalization}

The average hospitalization period for patients with incidental aneurysms who underwent GDC embolization (Groups 1 and 3) was 3 days. Patients returned to normal activities of daily living after very little time. The short hospitalization period yielded significant positive impact on patients social activity as well as reducing the cost to public health.

Yundt, et al.,[37] have reported hospital financial data of patients admitted with intracranial aneurysms. The average hospitalization period of patients with surgically treated unruptured aneurysms was 10.9 days, including 4.2 days in an intensive care unit.

\section{CONCLUSIONS}

Results of recent reports have demonstrated that intracranial aneurysms can be successfully obliterated by GDC endovascular technology.[6-8,19,22,24,31] In selected patients, this technology is less invasive than conventional vascular neurosurgery, and this may be particularly true in patients who present with incidental intracranial aneurysms.

The overall morbidity/mortality rate in this series is comparable to the best neurosurgical series for the treatment of incidental aneurysms. The combined procedural and clinical morbidity rate of the GDC technology has dramatically decreased in the last 2 years, due to the development of delivery systems and softer GDCs and the increased experience of the neurointerventional teams. The long-term anatomical results have also been improved by the combined utilization of 3-dimension coils, soft coils, and GDC balloon-assisted technology.

The results of this study indicate that GDC treatment of incidental aneurysms can be performed safely regardless of aneurysm location and patient medical conditions. The short hospitalization period provides significant benefit for patients' social activity and to public health by reducing costs.

\section{References}

1. Asari S, Ohmoto T: Long-term outcome of surgically treated unruptured cerebral aneurysms. Clin Neurol Neurosurg 96:230-235, 1994

2. Asari S, Ohmoto T: Natural history and risk factors of unruptured cerebral aneurysms. Clin Neurol Neurosurg 95:205-214, 1993

3. Atkinson JLD, Sundt TM Jr, Houser OW, et al: Angiographic frequency of anterior circulation aneurysms. J Neurosurg 70:551-555, 1989

4. Dell S: Asymptomatic cerebral aneurysm: assessment of its risk of rupture. Neurosurgery 10:162-166, 1982 
5. Drake CG: Management of cerebral aneurysm. Stroke 12:273-283, 1981

6. Graves VB, Strother CM, Duff TA, et al: Early treatment of ruptured aneurysms with Guglielmi detachable coils: effect on subsequent bleeding. Neurosurgery 37:640-648, 1995

7. Guglielmi G, Viñuela F, Dion J, et al: Electrothrombosis of saccular aneurysms via endovascular approach. Part 2: Preliminary clinical experience. J Neurosurg 75:8-14, 1991

8. Guglielmi G, Viñuela F, Duckwiler G, et al: Endovascular treatment of posterior circulation aneurysms by electrothrombosis using electrically detachable coils. J Neurosurg 77:515-524, 1992

9. Heiskanen O: Risk of bleeding from unruptured aneurysms in cases with multiple intracranial aneurysms. J Neurosurg 55:524-526, 1981

10. Heiskanen O: Risk of surgery for unruptured intracranial aneurysms. J Neurosurg 65:451-453, 1986

11. Inagawa T, Hirano A: Autopsy study of unruptured incidental intracranial aneurysms. Surg Neurol 34:361-365, 1990

12. Inagawa T, Hada H, Katoh Y: Unruptured intracranial aneurysms in elderly patients. Surg Neurol 38:364-370, 1992

13. Juvela S, Porras M, Heiskanen O: Natural history of unruptured intracranial aneurysms: a long-term follow-up study. J Neurosurg 79:174-182, 1993

14. Kassel NF, Torner JC, Haley EC Jr, et al: The International Cooperative Study on the Timing of Aneurysm Surgery. Part 1: Overall management results. J Neurosurg 73:18-36, 1990

15. King JT Jr, Berlin JA, Flamm ES: Morbidity and mortality from elective surgery for asymptomatic, unruptured, intracranial aneurysms: a meta-analysis. J Neurosurg 81:837-842, 1994

16. Khanna RK, Malik GM, Qureshi N: Predicting outcome following surgical treatment of unruptured intracranial aneurysms: a proposed grading system. J Neurosurg 84:49-54, 1996

17. McCormick WF, Acosta-Rua GJ: The size of intracranial saccular aneurysms. An autopsy study. J Neurosurg 33:422-427, 1970

18. Moret J, Cognard C, Weill A, et al: The "remodelling technique" in the treatment of wide neck intracranial aneurysms. Intervent Neuroradiol 3:21-35, 1997

19. Moret J, Pierot L, Boulin A, et al: Endovascular treatment of anterior communicating artery aneurysms using Guglielmi detachable coils. Neuroadiology 38:800-805, 1996

20. Moyes PD: Surgical treatment of multiple aneurysms and of incidentally-discovered unruptured aneurysms. J Neurosurg 35:291-295, 1971

21. Nakagawa T, Hashi K: The incidence and treatment of asymptomatic, unruptured cerebral aneurysms. J Neurosurg 80:217-223, 1994

22. Nichols DA, Brown RD Jr, Thielen KR, et al: Endovascular treatment of ruptured posterior circulation aneurysms using electrolytically detachable coils. J Neurosurg 87:374-380, 1997 
23. Piepgras D: Management of incidental intracranial aneurysms. Clin Neurosurg 35:511-518, 1989 24. Raymond J, Roy D, Bojanowski M, et al: Endovascular treatment of acutely ruptured and unruptured aneurysms of the basilar bifurcation. J Neurosurg 86:211-219, 1997

25. Rice BJ, Peerless SJ, Drake CG: Surgical treatment of unruptured aneurysms of the posterior circulation. J Neurosurg 73:165-173, 1990

26. Rinkel GJE, Djibuti M, van Gijn J: Prevalence and risk of rupture of intracranial aneurysms. A systemic review. Stroke 29:251-256, 1998

27. Ronkainen A, Puranen MI, Hernesniemi JA, et al: Intracranial aneurysms: MR angiographic screening in 400 asymptomatic individuals with increased familial risk. Radiology 195:35-40, 1995

28. Samson DS, Hodosh RM, Clark WK: Surgical management of unruptured asymptomatic aneurysms. J Neurosurg 46:731-734, 1977

29. Solomon RA, Fink ME, Pile-Spellman J: Surgical management of unruptured intracranial aneurysms. J Neurosurg 80:440-446, 1994

30. Ujiie H, Sato K, Onda H, et al: Clinical analysis of incidentally discovered unruptured aneurysms. Stroke 24:1850-1856, 1993

31. Viñuela F, Duckwiler G, Mawad M: Guglielmi detachable coil embolization of acute intracranial aneurysm: perioperative anatomical and clinical outcome in 403 patients. J Neurosurg 86:475-482, 1997

32. Wiebers DO, Torner JC, Meissner I: Impact of unruptured intracranial aneurysms on public health in the United States. Stroke 23:1416-1419, 1992

33. Wiebers DO, Whisnant JP, O'Fallon WM: The natural history of unruptured intracranial aneurysms. N Engl J Med 304:696-698, 1981

34. Wiebers DO, Whisnant JP, Sundt TM Jr, et al: The significance of unruptured intracranial saccular aneurysms. J Neurosurg 66:23-29, 1987

35. Wirth FP, Laws ER Jr, Piepgras D, et al: Surgical treatment of incidental intracranial aneurysms. Neurosurgery 12:507-511, 1983

36. Yoshimoto T, Mizoi K: Importance of management of unruptured cerebral aneurysms. Surg Neurol 47:522-526, 1997

37. Yundt K, Dacey RG Jr, Diringer MN: Hospital resource utilization in the treatment of cerebral aneurysms. J Neurosurg 85:403-409, 1996

Manuscript received August 18, 1998.

Accepted in final form September 21, 1998.

Address reprint requests to: Yuichi Murayama, M.D., Division of Interventional Neuroradiology, Department of Radiological Sciences, University of California, Los Angeles, School of Medicine and Medical Center, 10833 Le Conte Avenue, Los Angeles, California 90024. 